\title{
DISTRIBUSI NITRAT, OKSIGEN TERLARUT, DAN SUHU DI PERAIRAN SOCAH-KAMAL KABUPATEN BANGKALAN
}

\author{
DISTRIBUTION OF NITRATE, DISSOLVED OXYGEN AND TEMPERATURE \\ IN SOCAH WATERS, DISTRICT OF KAMAL, BANGKALAN
}

\section{Dewy Septiyanti Yolanda, Firman Farid Muhsoni, Aries Dwi Siswanto*}

Program Studi Ilmu Kelautan Universitas Trunojoyo Madura

Jl. Raya Telang PO.BOX 2 Kamal, Bangkalan, Madura, Jawa Timur

"Corresponding author email: ariesdwisiswanto@yahoo.co.id

Submitted: 23 Februari 2016 / Revised: 23 Februari 2016 / Accepted: 29 Oktober 2016

DOI: http://dx.doi.org/10.21107/jk.v9i2.1052

\begin{abstract}
The conditions and the dynamics of ocean waters is influenced by several parameters, including the parameters of physics, chemistry, biology, and others. Among the important parameters are nitrates, dissolved oxygen, and temperature. Those parameters are important because it affects the quality and condition of the waters, particularly in Socah waters, District of Kamal, Bangkalan. The purpose of this study was to determine the characteristics and distribution of nitrate, dissolved oxygen, and temperature in the Socah waters, Kamal, Bangkalan. The study was conducted in October 2014 with 10 sampling points. Nitrate was analyzed using spectrophotometry with a wavelength of $410 \mathrm{~nm}$ performed at the Laboratory of Marine Science Trunojoyo University of Madura. An analysis showed that nitrate concentrations ranging from 0002-0022 mg/l, dissolved oxygen ranges from 6.01 to $9.04 \mathrm{mg} / \mathrm{l}$, and the surface temperature ranges $29.0-32,7^{\circ} \mathrm{C}$. The analysis shows good condition and suitable for marine life appropriate quality standards set by the Ministry of Environment (KMNLH).
\end{abstract}

Keywords: Nitrates, Dissolved oxygen, Temperature, Socah waters

\begin{abstract}
ABSTRAK
Kondisi dan dinamika perairan laut sangat dipengaruhi oleh beberapa parameter, diantaranya adalah parameter fisika, kimia, biologi, dan lain sebagainya. Diantara parameter penting tersebut adalah nitrat, oksigen terlarut, dan suhu. Ketiga parameter ini penting karena berpengaruh terhadap kondisi dan kualitas perairan, khususnya di perairan Socah, Kecamatan Kamal, Kabupaten Bangkalan. Tujuan penelitian ini adalah untuk mengetahui karakteristik dan distribusi nitrat, oksigen terlarut, dan suhu di perairan Socah-Kamal Kabupaten Bangkalan. Penelitian dilakukan pada bulan Oktober 2014 dengan 10 titik sampling. Analisa nitrat dianalisa dengan menggunakan spektrofotometri dengan panjang gelombang $410 \mathrm{~nm}$ dilakukan di Laboratorium IImu Kelautan Universitas Trunojoyo Madura. Hasil analisa menunjukkan konsentrasi nitrat berkisar 0.002-0.022 mg/l, oksigen terlarut berkisar 6,01-9,04 mg/l, dan suhu permukaan berkisar 29.0-32, $7^{\circ} \mathrm{C}$. Hasil analisa menunjukkan kondisi baik dan cocok untuk kehidupan biota laut sesuai standar baku mutu yang sudah ditetapkan oleh Kementrian Negara Lingkungan Hidup (KMNLH).
\end{abstract}

Kata Kunci: Nitrat, Oksigen Terlarut, Suhu, Perairan Socah-Kamal 


\section{PENDAHULUAN}

Perairan Socah-Kamal merupakan perairan yang masih masuk dalam kawasan Selat Madura. Perairan sekitar Kamal Bangkalan merupakan daerah yang diduga mulai tercemar akibat kegiatan transportasi laut maupun kegiatan nelayan. Perairan Kamal juga menjadi penampung bahan buangan limbah pemukiman, industri pabrik, dan tambak. Faktor ini, baik secara langsung dan tidak langsung, dapat mempengaruhi parameter fisika dan kimia perairan (Aini, 2010). Selat Madura merupakan perairan yang sangat komplek, dalam hal ini disebabkan karena perairan Selat Madura memiliki manfaat yang sangat banyak. Adapun pada saat ini, pemanfaatan perairan Selat Madura meliputi: pelabuhan penyeberangan, alur pelayaran, penangkapan ikan, maupun ekspoitasi gas alam (Bahtiar, 2008). Kegiatan tersebut dapat berpotensi terhadap pencemaran laut, sehingga mempengaruhi terhadap fungsi dari lingkungan laut. Salah satu lingkungan laut yang dipengaruhi secara langsung oleh pencemaran laut adalah pantai.

Kondisi seperti ini dapat mengakibatkan perubahan kualitas perairan. Ippen (1966) mengatakan bahwa kondisi oseanografi dipengaruhi oleh banyak faktor baik yang eksternal maupun internal. Pengaruh eksternal dapat berasal dari laut lepas yang mengelilinginya, maupun yang berasal dari daratan yang berupa aliran air tawar menuju laut dari sungai. Sedangkan pengaruh internal seperti bentuk topografi dasar perairan. Gambaran dari oseanografi suatu perairan laut adalah distribusi atau penye-baran parameter fisika maupun kimia. Salah satunya adalah nitrat, oksigen terlarut dan suhu. Dalam aspek ekologi, penentuan nitrat, oksigen terlarut, dan suhu seringkali dinyatakan dalam kisaran nilai harian, mingguan atau musiman serta hasilnya pun berbeda di setiap perairan. Utamanya pada daerah yang berbatasan langsung dengan daratan dan lautan yaitu pantai.

Secara umum pantai didefinisikan sebagai daerah yang berada di tepi perairan yang masih dipengaruhi oleh air pasang tertinggi dan air surut terendah. Sedangkan perairan pantai merupakan perairan yang banyak menerima beban masukan bahan organik, baik secara alami maupun suplay dari lautan dan/atau daratan (Rokhim et al, 2009).
Bahan organik berasal dari berbagai sumber seperti kegiatan pertambakan, pertanian, pemukiman, industri, pertambangan, pelabuhan dan aktifitas manusia yang akan masuk melalui aliran sungai atau run-off yang berasal dari daratan (Rokhim dkk, 2009). Nitrat merupahan bahan organik yang dimanfaatkan oleh organisme laut. Akan tetapi keberadaannya juga harus dijaga. Kelebihan nitrat dapat berdampak buruk bagi lingkungan. Contoh dari kelebihan nitrat yaitu blomming alge.

Dalam suatu ekologi, sifat fisik dan kimia pada perairan sangat penting, karena kedua sifat ini dapat mempengaruhi pertumbuhan dan kelangsungan hidup biota perairan, seperti fitoplankton sebagai penghasil produktivitas primer (Khasanudin, 2012). Ardiansyah (2013) menyebutkan produktivitas primer dapat menurun seiring dengan konsentrasi padatan tersuspensi pada suatu perairan tinggi, dimana hal ini dapat mengganggu aktifitas fotosintesis.

Penelitian sebelumnya Saiwei dan Hongying (2004) mengatakan bahwa kadar nitrat lebih dibutuhkan fitoplankton bila dibandingkan dengan fosfat. Tingginya pengaruh daratan yang banyak menyuplai zat organik dari limbah antropogenik yang merupakan sisa atau buangan dari berbagai aktivitas manusia seperti rumah tangga, pemukiman, peternakan dan pertanian (Muchtar, 2012). Penelitian ini bertujuan untuk mengkaji distribusi nitrat, oksigen terlarut dan suhu sebagai parameter oseanografi diperairan Socah-Kamal Kabupaten Bangkalan.

\section{MATERI DAN METODE}

Pengamatan nitrat, suhu dan oksigen terlarut di perairan Socah-Kamal dilakukan dengan menggunakan perahu nelayan pada bulan Oktober 2014. Adapun jumlah titik pengambilan sampel sebanyak 10 titik (Gambar 1). Sampel air laut diambil dengan menggunakan botol polietilent pada permukaan. Untuk suhu dan oksigen terlarut dilakukan pengukuran secara in-situ dilapangan tepat pada titik sampel yang sudah di ploting pada GPS.

Sampel air laut yang sudah di dalam botol polietilent kemudian dilakukan penyaringan dengan menggunakan kertas saring, 
kemudian membuat larutan blanko dan standart, kemudian ketiga larutan yaitu sampel, blanko dan standart dimasukkan masing-masing $10 \mathrm{ml} \mathrm{H} 2 \mathrm{SO} 4,2 \mathrm{ml} \mathrm{NaCl}$, panaskan pada suhu $90^{\circ} \mathrm{C}$ dengan waktu 20 menit, kemudian masukkan asam sulfanilat $0,5 \mathrm{ml}$ setelah itu dianalisa dengan menggunakan alat spektrofotometer dengan panjang gelombang $410 \mathrm{~nm}$ untuk nitrat.

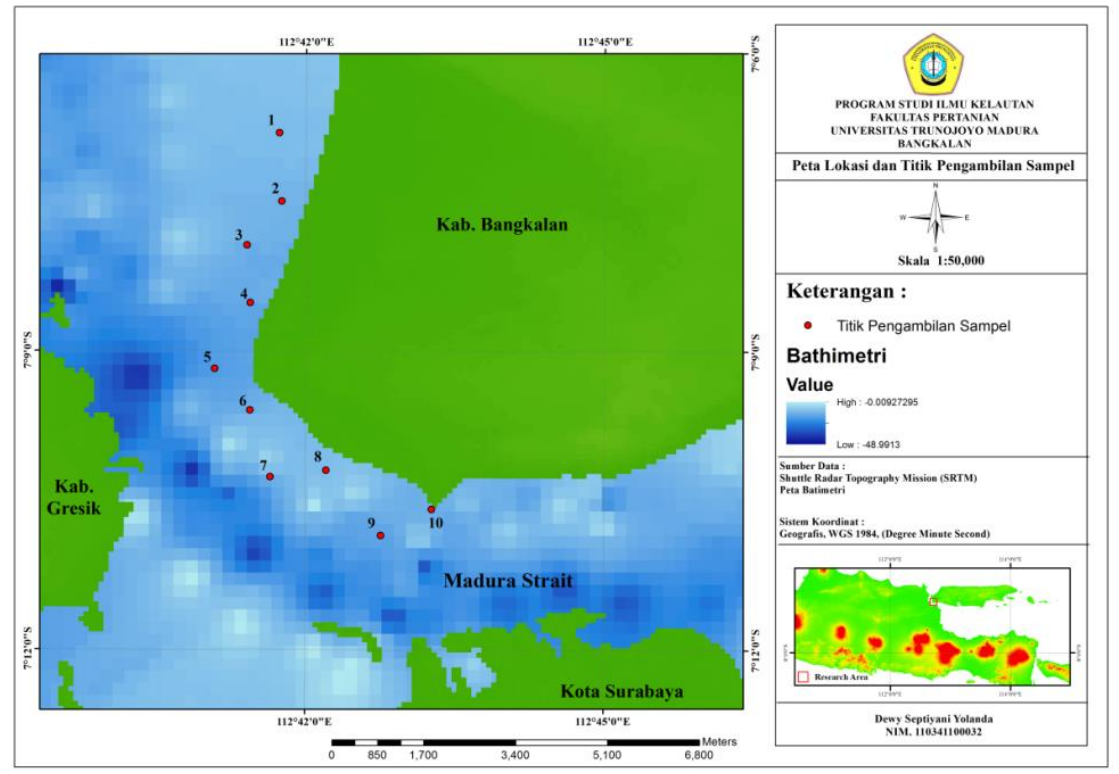

Gambar 1. Peta Lokasi Pengambilan Sampel

Hasil dari pembacaan absorbansi dilakukan perhitungan sebagai berikut:

NO3 $=\frac{1000 x A S x C s t x V s t}{V s x(\text { AstxAb })}$

Keterangan:

As : Absorbansi Sampel

Cst : Konsentrasi Standart $(0,07 \mathrm{M})$

Vst : Volume Standart $(10 \mathrm{ml})$

Vs : Volume Sampel $(10 \mathrm{ml})$

Ast : Absorbansi Standart

As : Absorbasi Blanko

\section{HASIL DAN PEMBAHASAN}

Kadar nitrat pada lapisan permukaan diperairan Socah-Kamal berkisar antara $0,002 \mathrm{mg} / \mathrm{l}-0,022 \mathrm{mg} / \mathrm{l}$ baik pada minggu pertama maupun minggu kedua. Secara horizontal terlihat bahwa kadar nitrat tertinggi minggu 1 dan 2 berada pada stasiun 2 dan 5 . Hal ini karena selain kadar nitrat berasal dari perairan itu sendiri juga dapat berasal dari sumbangan daratan berupa pertanian maupun limbah rumah tangga. Terlihat pada (Gambar 2) yang menunjukkan kadar nitrat tertinggi pada setiap stasiunnya dengan perbandingan waktu setiap minggunya.

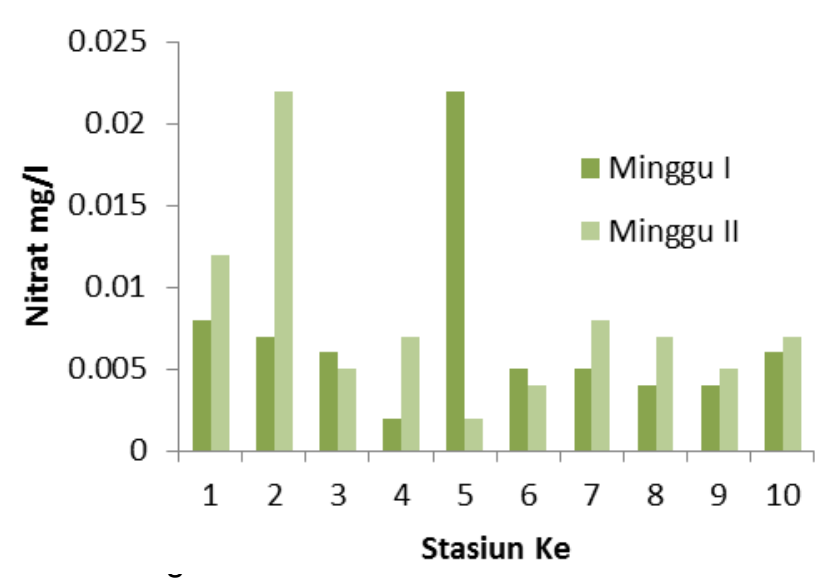

Distribusi nitrat diperairan Socah-Kamal yang terendah pada bagian selatan dan semakin tinggi menuju bagian utara yakni pada stasiun 1-5 (Gambar 2). Rendahnya kadar nitrat pada perairan Socah-Kamal ada hubungannya dengan kelimpahan fitoplankton yang tinggi (Fitriya, 2011), dengan ini kadar nitrat yang tinggi telah dikonsumsi oleh fitoplankton sebagai perkembangannya dan pertumbuhan hidupnya. Jones dan Lee (2005) menyebutkan bahwa nitrat merupakan parameter yang sangat berpengaruh terhadap kehidupan biota laut. Secara 
keseluruhan bahwa perairan Socah-Kamal masih layak untuk digunakan sebagai area budidaya, karena kadar nitrat tidak melebihi 0,9-3,2 mg/l (Baku Mutu Air Laut Departemen Pertanian dalam KMNLH 1984).

Berdasarkan (Gambar 3) terlihat bahwa kadar Oksigen terlarut pada minggu pertama dan kedua berkisar antara 6,06 mg/l-9,04 $\mathrm{mg} / \mathrm{l}$. Untuk kadar oksigen terlarut tertinggi pada stasiun 3 dan 4 sebesar $8,21 \mathrm{mg} / \mathrm{l}$ dan $9,04 \mathrm{mg} / \mathrm{l}$ pada minggu pertama dan tertinggi pada minggu kedua stasiun ke 2 dan 8 sebesar $7,72 \mathrm{mg} / \mathrm{l}$ dan $7,67 \mathrm{mg} / \mathrm{l}$. Tingginya kadar oksigen pada minggu pertama maupun kedua kondisi pengambilan pengukuran saat dilapangan air tidak begitu keruh sehingga, proses fotosintesis yang dilakukan oleh fitoplankton dapat berlangsung dengan baik. Rendahnya kadar oksigen di daerah pantai dekat muara sungai (estuari), erat kaitannya dengan kekeruhan air laut dan diduga disebabkan oleh semakin bertambahnya aktivitas mikroorganisme untuk menguraikan zat anorganik yang menggunakan oksigen terlarut (bioproses) pada perairan. DO yang sesuai dengan baku mutu air untuk perikanan $\geq 3$ $\mathrm{mg} / \mathrm{l}$. Kadar oksigen terlarut yang menyebabkan kematian dan pertumbuhan pada udang kurang optimal. Karena kelarutan oksigen dalam air dipengaruhi oleh faktor suhu dan kadar garam, jika kelarutan oksigen dalam air menurun, maka suhu dan kadar garam meningkat Hendrawati dalam Yolanda (2014).

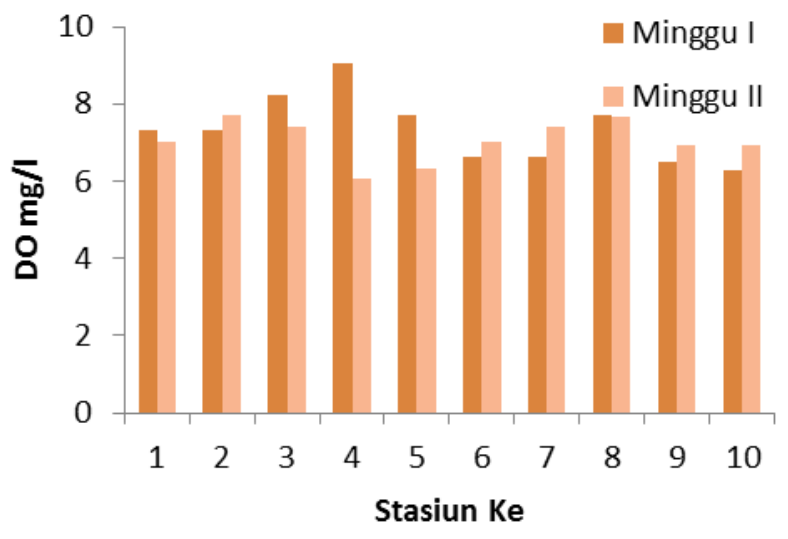

Gambar 3. Kadar Oksigen terlarut di perairan Socah

Secara horizontal oksigen terlarut semakin ke arah laut maka kadar oksigen terlarut akan semakin menurun. Namun hal ini tidak menjadi suatu ketentuan, bergantung pada karakteristik perairan itu sendiri (Nybakken, 1988). Kadar oksigen terlarut dalam suatu perairan akan menurun akibat proses pembusukan bahan organik, respirasi biota dan pelepasan oksigen ke udara. Oksigen berfungsi sebagai senyawa pengoksidasi dalam dekomposisi material organik yang akan menghasilkan zat hara. Nilai dari oksigen yang terlarut juga bervariasi antara hari ke hari maupun bulan ke bulan, namun variasi nilai yang terjadi tidak terlalu besar. Variasi yang terjadi ini diakibatkan oleh adanya pengaruh kondisi oseanografi seperti suhu, salinitas dan pergerakan angin. Pada profil permukaan laut konsentrasi untuk oksigen terlarut sangat bervariasi. Kondisi ini karena dipengaruhi oleh suhu. Semakin tinggi suhu maka semakin rendah kelarutan oksigen. Hal ini juga berbeda pada kedalaman laut yang hampir mencapai ratusan meter (Aini, 2011). Kelimpahan biota laut relatif masih terlihat berdasarkan nilai oksigen terlarut yang didapat di lapangan. Kadar oksigen terlarut yang paling baik untuk perikanan adalah 7-9 mg/l (Efendi, 2003).

Suhu air laut yang diperoleh berdasarkan pada hasil pengukuran yang dilkukan dua kali pada minggu pertama dan minggu kedua. Suhu pada minggu pertama berkisar antara $32,7^{\circ} \mathrm{C}-30,3^{\circ} \mathrm{C}$ dan minggu 2 sebesar $30,4^{\circ} \mathrm{C}-29^{\circ} \mathrm{C}$ (Gambar 4). Bervariasinya nilai suhu diperairan Socah-Kamal mengindikasikan bahwa, adanya faktor eksternal yaitu cuaca, angin dan arus. Pond and Pickard (1978) dalam Patty (2013) menjelaskan bahwa perubahan pola arus yang mendadak juga dapat menurunkan nilai suhu pada air. Selain itu Wenno (1981) mengatakan adanya variasi nilai suhu air laut disebabkan oleh proses alam seperti proses biokimia, yang melalui mikroorganisme yang dapat menghasilkan panas (reaksi endotermik dan eksotermik) serta proses mikrobiologis (sumber panas bumi).

Suhu sangat berpengaruh pada kadar nitrat pada suatu perairan karena dengan tingginya nilai suhu maka nitrat dalam perairan akan cepat menguap, sehingga saat pengambilan sampel contoh air laut menggunakan botol polietilent dan segera menyimpan sampel pada coolbox agar suhunya tetap stabil (Effendi, 2003). Lebih lanjut llahude dan Liasaputra (1980), rata - 
rata suhu permukaan air laut yang normal, yaitu berkisar antara $25,6-32^{\circ} \mathrm{C}$.

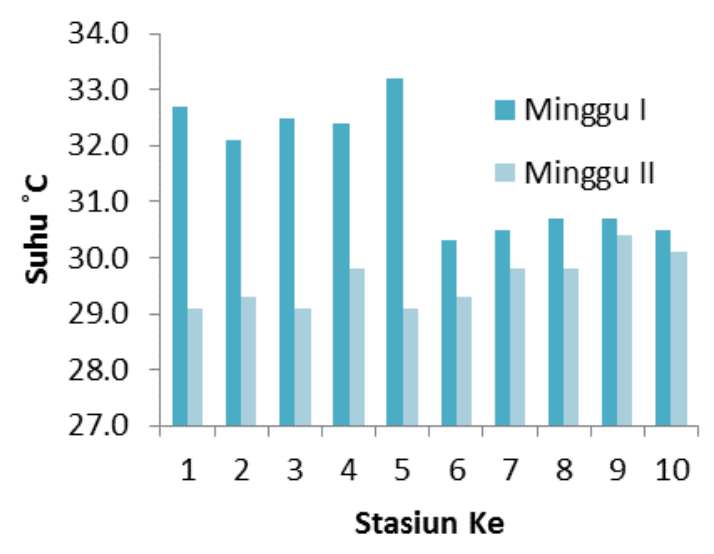

Gambar 4. Suhu di perairan Socah-Kamal, Bangkalan.

Berdasarkan gambar diatas minggu pertama lebih tinggi dibandingkan dengan minggu kedua yang mengalami penurunan. Kondisi ini dapat terjadi pada saat minggu pertama kondisi relatif panas dan angin bertiup cukup kencang. Namun pada minggu kedua pada perairan Socah turun hujan dan tiupan angin masih kencang sehingga suhu air lebih rendah dari minggu pertama. Kondisi suhu air disuatu perairan dipengaruhi terutama oleh kondisi atmosfer, cuaca dan intensitas matahari yang masuk ke laut (Officer, 1976). Secara umum suhu air diperairan berkisar antara $28,2-32,5^{\circ} \mathrm{C}$ dengan rata-rata antara $30,1 \pm 1,11^{\circ} \mathrm{C}$. Suhu pada lokasi penelitian menunjukkan masih berada pada kisaran suhu umumnya, dimana nilai suhu dilapisan permukaan laut yang normal berkisar 20$30^{\circ} \mathrm{C}$ (Nybakken, 1988).

Hubungan antara nitrat, oksigen terlarut dan suhu erat kaitannya dengan kondisi kualitas air. Penelitian Siwi (2014) mengatakan bahwa pada saat sea surface temperature rendah terjadi peningkatan pada konsentrasi nutrien. Konsentrasi nutrien bernilai minimum dipermukaan dan bertambah secara cepat terhadap kedalaman. Penurunan sea surface temperature yang diikuti dengan konsentrasi nutrien dan klorofil karena pengaruh kuat upwelling dari Samudra Hindia. Namun untuk oksigen terlarut menurut penelitian Ulqodry et al (2010) mengatakan bahwa proses dekomposisi bahan organik dilapisan dasar membutuhkan oksigen. Oksigen berfungsi sebagai senyawa pengoksidasi dalam dekomposisi material organik yang menghasilkan zat hara.

\section{KESIMPULAN DAN SARAN}

Distribusi nitrat, oksigen terlarut dan suhu selain dipengaruhi oleh perairan itu sendiri, juga dipengaruhi oleh lingkungan serta pola arus diperairan tersebut. Secara keseluruhan hasil analisa dan pengukuran nitrat, oksigen terlarut dan suhu diperairan SocahKamal masih baik untuk kehidupan biota laut mengacu pada standart baku mutu yang sudah ditetapkan oleh Kementrian Negara Lingkungan Hidup (KMNLH).

\section{DAFTAR PUSTAKA}

Aini, K. W. (2010). Kelimpahan Fitoplankton Di Perairan Kamal Bangkalan. Praktek Kerja Lapang. Jurusan IImu Kelautan. Fakultas Pertanian. Universitas Trunojoyo Madura: Bangkalan.

Ardiansyah, P. (2013). Studi Karakteristik Pasang Surut dan Pengaruhnya Terhadap Sebaran Total Suspeded Solid (TSS) Di Perairan Selat Madura Kabupaten Bangkalan. Skripsi. Universitas Trunojoyo Madura: Bangkalan.

Bahtiar, R. (2008). Penilaian Despresiasi Sumberdaya Perikanan Di Selat Madura Provinsi Jawa Timur. [Thesis]. Program Pascasarjana Institut Pertanian Bogor: Bogor.

Effendi, H. (2003). Telaah Kualitas Air. Jurusan Managemen Sumberdaya Perairan. Fakultas Perairan dan IImu Kelautan. IPB: Bogor.

Fitriya, N. (2011). Laporan Akhir Ekspidisi Widya Nusantara (E-WIN). Penelitian Biodiversitas dan Kondisi Oseanografi di Kawasan Perairan Kepulauan Natuna, Pusat Penelitian Oseanografi - LIPI. 322 hal.

Ippen, A. T. (1966). Estuary and Coastiline Hydrodynamics. Mc Graw-Hill Book Company, Inc: 744 pp.

Jones-Lee, A., \& Lee, G. F. (2005). Eutrofication (Excessive Fertilization) Water Enyclopedia: Surface and Agricultural water. Wiley, Hoboken, NJ. 107-114 pp.

Jorgensen. S. E. (1990). Lake Management. Pergamon Press Ltd. Oxford Great Britain. 
Khasanudin. M. N. (2012). Studi Konsentrasi Nitrat dan Phosphate Di Muara Sungai Wonorejo Kecamatan Gunung Anyar Kotamadya Surabaya. Praktek Kerja Lapang. Jurusan IImu Kelautan. Fakultas Pertanian. Universitas Trunojoyo Madura: Bangkalan

Kementerian Mentri Negara-Lingkungan Hidup (KMNLH) (1988). Baku Mutu Air Laut Untuk Biota Laut. Dalam: Bahan Penyusunan RPP Baku Mutu Air Laut Untuk Mandi, dan Renang, Biota Laut dan Budidaya Biota Laut. Jakarta: 32 hal.

Muchtar, M. (2012). Distribusi Fosfat, Nitrat dan Silikat Di Perairan Kepulauan Natuna. Pusat Penelitian Oseanografi - LIPI: Jakarta.

Nybakken, J. W. (1988). Biologi Laut: Suatu Pendekatan Ekologi. Terjemahan dari Marine Biology: An Ecology Approach, oleh Eidman, M, Koesoebiono, D. G, Bengen, M, Hutomo dan S. Sukardjo. PT. Gramedia: Jakarta, xv.459 hlm.

Officer, C. B., (1976). Physical Oseanography of Estuaries and Associated Costal Waters. John Willey and Sons. New Tork: 465 pp.

Patty, S. I. (2013). Distribusi Suhu, Salinitas dan Oksigen Terlarut Di Perairan Kema, Sulawesi Utara. Jurnal IImiah Planax. Vol. 1(3). ISSN: 2302-3589.

Rokhim, K., Arisandi. A., \& Abida, I. W. (2009). Analisa Kelimpahan
Fitoplankton dan Ketersedian Nutrien (NO3 dan PO4) Di Perairan Kecamatan Kwanyar Kabupaten Bangkalan. Jurnal Kelautan, 2(2). ISSN: 1907-9931.

Saiwei, C., \& Hongying, L. (2004). Distribution of Dissolved Inorganik Phosphat in Nansha Island Sea Area, South China Sea. Marine Science Bulletin, 6(1), 32-37.

Siwi, W. E. R. (2014). Distribusi Suhu Terhadap Distribusi Klorofil-A dan Nutrien (Fosfat, Amoniak, Silikat) Diperairan Selat Bali Periode Pengukuran April, Juni dan Agustus 2013. Balai Penelitian dan Observasi Laut: Bali.

Ulqodry T. Z., Yulisman, \& Syahdan, M., \& Santoso (2010). Karakteristik dan Sebaran Nitrat, Fosfat dan Oksigen Terlarut Di Perairan Karimunjawa, Jawa Tengah. Jurnal Penelitian Sains. Volume 13(1).

Wenno, L. F. (1981). Laporan Penelitian: Sifat-Sifat Oseanologi Perairan Dangkal Maluku. Proyek Penelitian dan Pengembangan Sumberdaya Laut Perairan Maluku (1980-1981). LON-LIPI, SPA, Ambon: 185 hal.

Yolanda, D. S. (2014). Kajian Parameter Fisika dan Kimia Serta Sebaran Nitrat Di Perairan Socah-Kamal, Kabupaten Bangkalan, Madura. Skripsi. Universitas Trunojoyo Madura: Bangkalan. 